\title{
MuITOS Mundos E A INTERPRETAÇÃO ONDULATÓRIA: REVENDO A CONEXÃO À LUZ DA FILOSOFIA SCHRÖDINGERIANA
}

\author{
Caroline Elisa MurR
}

\begin{abstract}
This paper presents Erwin Schrödinger's Wave Interpretation of Quantum Mechanics, with the main goal of comparing it to the so called Many Worlds Interpretation, of which Bryce DeWitt is the most important figure. It is commonly said that DeWitt's and Everett's Interpretations are equivalent, and both would have been inspired by Schrödinger's wave-like approach. This paper claims those stances to be superficial, requiring a more detailed exam of the philosophical grounds held by the authors, besides other distinguishing details. A connexion may be established concerning the rejection of the quantum collapse, although one should be careful about the meaning of the term in each standpoint. This article also shows the balance of Schrödinger's Interpretation of Quantum Mechanics in regard to his philosophy in a wider sense. Finally, it concludes that detaching Schrödinger's interpretation from Many Worlds is more coherent with his philosophical assumptions; he conceives a single world containing infinite possibilities.
\end{abstract}

Keywords: Schrödinger; wave interpretation; many worlds; quantum mechanics; Everett; quantum collapse.

\section{Introdução}

Na década de 1970, Bryce DeWitt, físico norte-americano, lança juntamente com outros físicos as ideias referentes a uma interpretação da mecânica quântica que ficou conhecida como "interpretação dos muitos mundos". ${ }^{1}$ Nela, DeWitt faz uma releitura das ideias de outro físico também americano, Hugh Everett, que apresentou uma interpretação da mecânica Quântica na década de 1950. Segundo Jeffrey Barrett, a leitura de Everett feita por parte de DeWitt teria ficado mais conhecida do que a própria interpretação everettiana, o que gera confusão entre as posições de cada um deles até hoje (Barrett 2014, seção 7).

Outra confusão comum, cuja origem autoral é difícil de constatar, liga de alguma forma Erwin Schrödinger, físico e filósofo austríaco, à IMM. É comum a menção a uma inspiração em Schrödinger por parte dos idealizadores dessas interpretações, em virtude de que elas compartilham sua visão quanto à negação do colapso na mecânica quântica (ver Gribbin 2013, p.662; Bitbol 1995, p.17; Allori et al 2011). Quanto a esse ponto, a inspiração é defensável, mas influências mais profundas para além da mera inspiração são difíceis de sustentar, conforme veremos ao longo deste artigo. Além disso, a própria visão do colapso parece diferir nesses autores, o que torna discutível procurar aproximá-los, mesmo que apenas quanto à rejeição do colapso.

Principia 19(3): 343-361 (2015).

Published by NEL — Epistemology and Logic Research Group, Federal University of Santa Catarina (UFSC), Brazil. 
Aprofundando um pouco mais esse exame, perceberemos que a ideia geral de IMM destoa em muitos pontos da filosofia schrödingeriana como um todo. O mesmo ocorre com a interpretação de Everett e a IMM. É difícil sustentar, portanto, que haja semelhanças estreitas entre os aspectos filosóficos presentes nas três interpretações: IMM, Everett e a interpretação ondulatória de Schrödinger. ${ }^{2}$

Neste artigo, retratamos a interpretação de Schrödinger procurando, ao mesmo tempo, evidenciar as nuances do seu pensamento filosófico, visto de maneira mais geral, que são harmônicas com a interpretação que ele formulou para a mecânica quântica. Além disso, apresentamos brevemente um panorama das interpretações de muitos mundos, que foram lançadas por DeWitt, mas receberam variantes desde então. Também fazemos uma exposição sucinta da interpretação de Everett, visando a esclarecer as diferenças para com IMM. Por fim, argumentamos sobre as diferenças entre IMM, Everett e IOS, bem como sobre a inconsonância entre algumas das ideias subjacentes aos três pontos de vista.

Assim, indicamos que não é coerente derivar IMM de IOS, em virtude de suas muitas dessemelhanças, que vão desde as bases filosóficas até detalhes do ponto de vista físico. Fazemos também alguns comentários comparando IOS à interpretação de Everett, procurando esclarecer pontos comuns e divergentes entre as duas visões. Desse modo, também exploramos melhor a interpretação ondulatória de Schrödinger, do ponto de vista filosófico, complementando a perspectiva geral da sua filosofia. A sua harmonia interna é mantida ao considerar-se mais esse aspecto de seu pensamento, concernente à sua visão da mecânica quântica. Por essa razão, não vamos aqui analisar minuciosamente detalhes técnicos relativos à física ou à matemática, dando ênfase, no caso das três interpretações aqui tratadas, aos aspectos filosóficos a elas relacionados.

\section{A interpretação ondulatória de Schrödinger - IOS}

Schrödinger tinha pontos de vista muito diferentes dos físicos pertencentes ao chamado "grupo de Copenhague", representantes da que ficou conhecida como "interpretação ortodoxa" da mecânica quântica. Essas divergências abrangiam desde bases filosóficas subjacentes às suas ideias até detalhes técnicos relativos à formulação matemática e física da teoria que esses físicos, juntos, ajudaram a desenvolver. A interpretação ortodoxa, juntamente com o formalismo de von Neumann, acabaram sendo preferidas no decorrer do desenvolvimento e consolidação da teoria (Murr 2010, p.59). Por uma série de motivos, Schrödinger criticava a "atitude geral" seguida na mecânica quântica (Schrödinger 1995 [1955], p.109). Mas a sua própria concepção não foi muito clara durante muito tempo; Michel Bitbol diz que Schrödinger não a apresentou de forma lúcida e madura até a década de 1950, tendo mudado de posição ao menos quatro vezes em quase 30 anos, desde 1926 (Bitbol 1995, p.1).

Principia 19(3): 343-361 (2015). 
Schrödinger tinha como característica, mesmo um traço marcante de sua personalidade, fazer críticas. Mesmo que não pudesse apresentar uma solução melhor do que aquela contra a qual se voltava, ele não deixava de apontar o que via como pequenas falhas ou como problemas sérios nas concepções de outros, especialmente do grupo de Copenhague. Para ele, Heisenberg, Bohr e muitos dos que compartilhavam de suas visões guardavam "esqueletos no armário", esquecendo-se deles e levando o trabalho adiante, por vezes ignorando grandes questões que os deveriam fazer retroceder. Ele diz: "Nos vinte anos da sua existência, sérias objeções têm sido levantadas uma após a outra contra a interpretação corrente. Algumas delas não foram resolvidas mas arquivadas." (Schrödinger 1995 [1949], p.103). ${ }^{3}$

Não fosse essa sua peculiaridade - que muitas vezes beirava a teimosia - e ele não teria insistido durante quase trinta anos em construir não só uma interpretação própria da mecânica quântica, como também um pensamento filosófico particular. Ambos são harmoniosos, sendo talvez esse o principal motivo para a demora na construção dessa interpretação física - ela deveria surgir concomitantemente ao amadurecimento de sua filosofia. Por isso, a IOS só pôde aparecer em sua forma mais madura na década de 1950, enquanto Schrödinger também procurava lapidar suas reflexões filosóficas de forma mais clara.

As quatro variantes da IOS podem ser vistas, segundo Bitbol, como "passos em um projeto de reconstrução ontológica", não constituindo fases totalmente diferentes nem mudanças radicais nas bases de seu pensamento (Bitbol 1995, p.1). Ele pretendia, de fato (ou pelo menos deu-se conta disso em suas concepções mais tardias), que IOS fosse não só uma interpretação mas apresentasse uma nova ontologia para a mecânica quântica, em termos de ondas. É preciso apreender isso de início, a fim de compreender como Schrödinger concebia a interpretação ondulatória. Ademais, dois pontos importantes precisam ser destacados antes de prosseguirmos: por que a ontologia anterior era insatisfatória e por que se podia pensar em uma ontologia específica para essa parte de uma teoria física.

Começaremos pela última das duas questões citadas. A liberdade de Schrödinger em idealizar essa ontologia vem das concepções filosóficas que embasam seu pensamento sobre a natureza da ciência. Para Schrödinger, não é possível haver correspondência entre as descrições científicas e a realidade exterior à ciência. Tal concepção fica clara ao longo de sua obra, sendo expressa, por exemplo, no trecho a seguir: "Mas que uso se faz dessa descrição, a qual, como eu disse, não se acredita descrever fatos observados ou como a natureza é realmente? Bem, acredita-se que ela nos dá informação sobre fatos observados e sua dependência mútua." (Schrödinger 1996 [1951], p.145).

Logo, para Schrödinger, a física não teria nenhuma obrigação de fazer seus objetos corresponderem àqueles com que convivemos na realidade cotidiana; sua única função seria nos fornecer informação sobre o mundo observável. O que a física faz é 
construir de certa forma uma outra parcela da realidade, a qual tem conexões indiretas com o mundo empírico. Os objetos e o universo da física são reais, também, em um sentido menos metafísico e mais metodológico (ver Murr 2011, p.86-8). Portanto, é perfeitamente plausível reconstruir a ontologia da mecânica quântica, libertando-a das amarras tanto da ontologia clássica quanto de linguagens e teorias que não se encaixam mais na nova dinâmica dos processos quânticos. Vale ressaltar que essa reconstrução não pode ocorrer livremente, mas de acordo tanto com preceitos filosóficos quanto teóricos e experimentais que se desenvolvem no novo paradigma.

Quanto ao segundo ponto, a razão pela qual a ontologia anteriormente adotada na mecânica quântica não era satisfatória dizia respeito a como os corpos físicos eram concebidos. Estes eram idealizados como objetos, semelhantemente às coisas que nos rodeiam na vida cotidiana. Algumas características lhes eram comuns, em especial a individualidade e a identidade. No entanto, os objetos alvo de experimentos na física quântica apresentavam-se difíceis de se enquadrar nessa caracterização. A dualidade onda-partícula era alvo de discussão e alguns procuraram antes de Schrödinger, ou ao mesmo tempo que ele, propor novos tipos de entidades que explicassem o comportamento da luz e dos elétrons, por exemplo, em certos experimentos (ver Pessoa Jr. 2003, p.4-6). Para Schrödinger, nenhuma das descrições isoladamente era adequada, e mais: tampouco a junção das duas serviria aos seus propósitos. Era certo que descrições em termos de corpos individuais deviam ser abandonadas, para ele, mas tampouco outras descrições existentes pareciam ser apropriadas - mesmo a combinação entre a corpuscular e a ondulatória. Ele queria algo realmente novo, que ao mesmo tempo desse conta das explicações físicas e fosse condizente com suas premissas filosóficas.

Buscando essa descrição, Schrödinger passa por algumas fases até encontrar sua interpretação ondulatória tardia, que não é equivalente à formulação inicial de 1926. Nesse processo, ele chega a resignar-se à interpretação de Copenhague (ver Bitbol 1995, p.3), período que acabou se revelando importante para que ele tivesse contato com visões mais instrumentalistas da ciência, que viriam a contribuir para sua acepção mais madura, embora esta seja mais próxima de uma espécie de realismo. Nesse sentido, o ponto crucial da transformação em seu pensamento foi a separação entre representações científicas e os fatos e processos naturais, na década de 1950 . Ele afirma:

Damos uma descrição completa, contínua no espaço e no tempo sem deixar nenhuma lacuna - uma descrição de algo. Mas não afirmamos que esse 'algo' são os fatos observados ou observáveis; muito menos declaramos que então descrevemos o que a natureza (matéria, radiação etc) realmente é." (Schrödinger 1996 [1951], p.144).

Por fim, Schrödinger pretende abandonar, na mecânica quântica, a ontologia tradicional dos corpos individuais localizados, propondo uma ontologia de ondas- $\Psi$ (Bit- 
bol 1995, p.4-5). Conforme veremos, isso é mais condizente com o seu tratamento da construção dos objetos da realidade do que a concepção clássica de partícula.

A desestruturação do colapso quântico é partilhada por essa interpretação tardia de Schrödinger, IMM e a interpretação de Everett, conforme ficará mais claro ao discutirmos especificamente essas interpretações. Entretanto, trata-se apenas de uma consequência de um esquema mais complexo, envolvido na construção da própria interpretação schrödingeriana da mecânica quântica. O colapso é descartado e não propriamente rejeitado, sendo deixado de lado junto com todo um esquema de pensamento a ser abandonado. A partir do momento em que se tem uma interpretação e uma descrição ondulatória que dão conta de todas as explicações necessárias na mecânica quântica, o colapso torna-se simplesmente desnecessário, na visão de Schrödinger, assim como os saltos quânticos e as probabilidades (Schrödinger 1995 [1952a], p.23). Além disso, Schrödinger não admitia que se usassem dois tipos de leis para lidar com as funções de onda, pois a descrição ondulatória seria suficiente. Ele diz sobre a lei de acordo com a qual a função de onda muda com o tempo, isto é, a equação de onda: "Se essa lei é aceita — e ela é universalmente aceita como uma lei geral - deve-se mantê-la. Ela não deve ser ocasionalmente infringida por um homem fazendo uma medição" (Schrödinger 1995 [1952a], p.83).

No entanto, o problema de explicar a transição de uma descrição contínua (ondulatória, no caso de IOS) para a descontinuidade vista na prática nos experimentos quânticos - conhecido como "problema da medição quântica", continuou sendo a maior dificuldade de Schrödinger, não satisfatoriamente superada (ver Bitbol 1995, p.18). Como veremos, Everett pretende resolver a questão incluindo a medição na subjetividade do observador. A solução esboçada por Schrödinger, embora não envolvesse o observador, mas união de aparato experimental e sistema físico, também toma direção parecida. Na sua descrição, de acordo com Bitbol, não haveria colapso mas sim "emaranhamento" ("entanglement"), com a função de onda do sistema quântico se dissolvendo na do sistema somado ao aparato (Bitbol 1995, p.14). Mais que uma superposição quântica, tem-se aí a ideia de superposição entre entidades quânticas e macroscópicas - algo que Schrödinger não aceitava com facilidade (ver Murr 2010, p.57-8). Por isso, o problema estaria longe de ser resolvido, para ele.

Diante dessas dificuldades, Schrödinger via a necessidade de se construir não só uma nova ontologia para a mecânica quântica, mas também uma nova teoria da medição quântica, projeto que permaneceu inacabado.

\section{Ontologia de "ondas- $\Psi$ "}

Por que a insistência de Schrödinger com respeito às ondas? Ele estava absolutamente convencido de que a mecânica ondulatória poderia dar conta de todos os grandes

Principia 19(3): 343-361 (2015). 
problemas que via com relação aos processos quânticos; além disso, as ondas, sob determinada descrição, constituíam-se nas entidades perfeitas para compor a nova ontologia que ele estava construindo. Mas que razão levou Schrödinger a propor descrições ondulatórias, em primeiro lugar? A resposta parece estar no início de sua carreira como físico, quando Schrödinger estuda a fundo a ondulatória em suas pesquisas sobre eletromagnetismo e radiação (ver Moore 1989, p.58-61 e p.67-70). É possível notar a força dessa influência em textos posteriores, em que Schrödinger usa exaustivamente os exemplos da acústica e da representação ondulatória da luz e das cores a fim de fortalecer suas argumentações (ver Schrödinger, 2001 [1956], capítulo 6).

Sua predileção pelas ondas pode ter sido despertada ao acaso, mas ele soube no futuro usar todas as vantagens dessas descrições na defesa de sua interpretação vantagens que talvez ele só conseguisse extrair devido à habilidade e experiência em trabalhar com elas, teórica e experimentalmente. Schrödinger sustenta que as ondas, construídas de determinada maneira (multidimensionais, mais exatamente), trazem em si os aspectos corpuscular e ondulatório, ou longitudinal e transversal, necessários às explicações dos fenômenos quânticos (Schrödinger 1995 [1952a], p.20).

Diante da explícita rejeição de Schrödinger a uma descrição corpuscular, a situação da dualidade quântica é assim expressa por Bitbol:

... mesmo que o conceito de trajetória pudesse ser mantido, apenas forneceria o entrelaçamento longitudinal entre os eventos, enquanto que os fenômenos quânticos também apresentam um entrelaçamento transversal, o qual se manifesta através dos padrões de interferência. (Bitbol 1995, p.9).

Isto é, os fenômenos quânticos exigem que os dois aspectos - longitudinal e transversal - estejam presentes na descrição. A complementaridade de Bohr entre onda e partícula ${ }^{4}$ não seria, segundo Schrödinger, a solução para essa situação; ele procurava um só quadro que satisfizesse ambos os padrões ao mesmo tempo, e encontrou-o na ondulatória:

A observação nos apresenta dois tipos de ligação estrutural entre os eventos, que podemos distinguir como a ligação longitudinal, usualmente chamada de aspecto corpuscular, e a ligação transversal, usualmente chamada de aspecto ondulatório. [...] Em um fenômeno ondulatório tem-se - não sempre, mas em muitos casos - os dois aspectos complementares das superfícies de onda (ou de fase) e de normais de ondas de raios. [...] Essas duas características, superfícies de onda e normais de onda, parecem capazes de representar as duas características observadas, a saber o entrelaçamento estrutural transversal e longitudinal, respectivamente." (Schrödinger 1995 [1952a], p.20).

Logo, a convivência das superfícies e das normais de ondas dariam conta dos dois aspectos que os fenômenos quânticos aparentemente impunham.

Principia 19(3): 343-361 (2015). 
Assim, as ondas pareciam a descrição mais adequada. Mas para Schrödinger não se trataria apenas de descrição. A construção da nova ontologia visava a passar de uma concepção abstrata das ondas- $\Psi$ para algo mais palpável, embora não em sentido metafísico forte. Schrödinger continuava rejeitando a correspondência metafísica entre as teorias físicas e a realidade cotidiana (ver Bitbol 1995, p.10). Por isso a separação que ele faz entre esses dois domínios, separação essa que exclui o realismo científico "puro" de suas concepções. Chamamos de puro aquele realismo científico de acordo com o qual as teorias correspondem à realidade ou partes dela, nos referindo ao que se entende por "realidade cotidiana" em uma abordagem schrödingeriana.

As ondas- $\Psi$ seriam mais adequadas ao realismo científico schrodingeriano. Em primeiro lugar por não ser necessário procurar na realidade cotidiana por algo a que devessem corresponder. São entidades construídas de acordo com certos padrões, como é comum aos objetos científicos, de acordo com Schrödinger. Em segundo lugar, tais ondas permitiriam a coexistência de realidades e virtualidades em sua constituição: seriam entidades abertas em expectativas e possibilidades. As virtualidades eram, para Schrödinger, importantes na definição dos objetos reais e, consequentemente, da própria realidade, especialmente científica (Bitbol 1995, p.6). Ele considera as expectativas sobre os objetos como parte integrante de sua constituição, o que os torna abertos a mudanças. Como Schrödinger equipara as construções científicas e cotidianas, para ele deveria haver lugar para as 'possibilidades', além dos resultados experimentais, em uma ontologia que pretendesse dar conta de objetos construídos pela ciência. As ondas- $\Psi$ são multidimensionais, comportando esse aspecto exigido por Schrödinger e revelando-se, no seu entender, como a entidade mais adequada para compor a base de uma ontologia para a mecânica quântica não-relativística.

As possibilidades estão, assim, incluídas na própria constituição dos objetos, não precisando sair do mundo ou realidade atual para se realizarem em mundos possíveis. O que há, para Schrödinger, são possibilidades que perfazem a constituição da própria realidade científica com que lidamos neste mundo atual em que estamos inseridos.

Nesse sentido, pode-se dizer que as possibilidades da superposição, por exemplo, não são alternativas, mas constituintes simultâneos da realidade. No caso do experimento do gato de Schrödinger, as expectativas de se encontrar o gato vivo ou o gato morto ao abrirmos a caixa perfazem uma realidade, em que o sistema está em estado de superposição. A presença das diversas expectativas é parte do caráter ontológico desse sistema.

A maior dificuldade dessa visão ontológica reside na conexão do aspecto empírico e da contraparte virtual da realidade. Apesar de Schrödinger conceber a realidade como agregado de acontecimentos simultâneos reais e virtuais, o problema da medição ainda ficava sem solução e ele não conseguia explicar satisfatoriamente a ligação entre os fatos empíricos e a sua descrição ondulatória (ver Bitbol 1995, p.12). A separação que Schrödinger implica entre as esferas cotidiana e científica gera a ne- 
cessidade do que ele chama de "Interpretação", isto é, como fazer e explicitar a ponte entre as teorias cientificas e os experimentos empíricos, os quais ocorrem no âmbito do mundo cotidiano. Mas Schrödinger nunca conseguiu construir satisfatoriamente tal ligação nem explicá-la exaustivamente.

Antes de abordar a consonância dessa visão sobre a constituição das ondas- $\Psi$ com a concepção schrödingeriana dos objetos científicos (e também cotidianos), vamos descrever brevemente a caracterização dessas ondas multidimensionais enquanto entidades básicas dessa ontologia. Observemos as vantagens explicitadas por Schrödinger para com os outros tipos de descrição.

Em primeiro lugar, as ondas não exigem que ambos, momento e posição, sejam medidos, como na representação corpuscular. $\mathrm{O}$ valor preciso de apenas um dentre eles basta para que a função de onda fique perfeitamente definida. Estaria resolvido, com isso, o problema do princípio da incerteza, segundo o qual não se pode medir, em experimentos quânticos, ambos esses valores com precisão (Pessoa Jr. 2003, p.1). Isso não é um problema para a mecânica ondulatória de Schrödinger, que parece mais adaptada a essa situação. Schrödinger esclarece inclusive que a mecânica ondulatória não apresenta conflito com o princípio da incerteza; a visão das probabilidades é que traz dificuldades:

A mecânica ondulatória nunca pode entrar em conflito com o P.I. [princípio da incerteza]. O conflito é produzido quando se impõe à mecânica ondulatória a abordagem das probabilidades. Essa visão tem como consequência a lei de que na medição a validade da equação de onda é momentaneamente suspensa e a função de onda muda abruptamente de uma forma não controlada por, nem estritamente variando com, a equação de onda, em nosso caso: o colapso de toda a onda esférica em uma parcela de onda pequena. É assim que obtemos — de duas maneiras diferentes — a acurácia do momento, a qual conflita com a acurácia da localização obtida em A: violando os princípios da mecânica ondulatória. (Schrödinger 1995 [1952a], p.35).

Em segundo lugar, há a eficácia notada nas funções de onda em incorporar conexões necessárias entre eventos experimentais. A ocorrência dos eventos experimentais, isoladamente, importava menos para Schrödinger do que a representação dessas conexões de maneira ordenada, como através da evolução das funções de onda no tempo, única exigência das leis da mecânica quântica. Essa eficiência é mais importante para definir a qualidade 'real' para essas funções de onda do que a sua correspondência com algum evento experimental que de alguma forma se propusesse a verificá-las empiricamente. Esse aspecto ressaltado por Schrödinger conecta-se bem às especificidades de seu realismo científico, e talvez, se melhor desenvolvida, poderia servir como escape ao problema da medição. Segundo o que entendemos como "realismo científico schrödingeriano", os objetos da ciência devem ser considerados reais (para uma definição menos metafísica de realismo) ao se mostrarem eficientes 
como guias de predições que levam a guias para ações (ver Murr 2011). As funções de onda cumprem esse papel, pois explicam de maneira satisfatória a evolução dos fenômenos no tempo.

Outro ponto positivo da abordagem ondulatória, de acordo com Schrödinger, é que as funções de onda da mecânica quântica indicam diretamente acontecimentos simultâneos ao invés de alternativas. A visão em termos de alternativas, que traz a necessidade do colapso, só é exigida por causa da insistência na explicação corpuscular:

A compulsão de substituir os acontecimentos simultâneos, como indicado diretamente pela teoria, por alternativas, das quais a teoria supostamente deve indicar as probabilidades, vem da convicção de que o que realmente observamos são partículas - que os eventos reais sempre concernem partículas, não ondas. (Schrödinger 1995 [1952a], p.20).

O abandono da concepção corpuscular permite que se utilize a simultaneidade expressa pelas funções de onda na constituição dos novos objetos. É possível, assim, que a obsessão pelas alternativas, na expressão das probabilidades, seja descartada. O colapso mais uma vez mostra-se desnecessário, de acordo com essa visão.

Por último, Schrödinger alega que as ondas- $\Psi$ são indivíduos, sem precisar ser individualizadas através de uma trajetória, como é o caso das partículas. Não é possível 'marcar' as partículas, mas apenas identificá-las através das trajetórias, segundo Schrödinger. As ondas, por outro lado, são reidentificáveis a partir de sua modulação de frequência ou amplitude:

Pelo contrário, ondas podem ser facilmente marcadas, pela sua forma ou modulação. [...] Se a sua esposa grita com você do jardim, você reconhece a voz dela e você sabe que as ondas de som que alcançam os seus ouvidos são as mesmas que ela produziu com suas cordas vocais. Esses são exemplos macroscópicos triviais. Mas as ondas da mecânica quântica exibem a mesma característica. Elas precisam ser tratadas como indivíduos. (Schrödinger 1995 [1952a], p.20).

Esse trecho revela algo que pode parecer surpreendente, levando em conta a ideia conhecida segundo a qual Schrödinger é contrário ao conceito de identidade na física quântica. ${ }^{5} \mathrm{Na}$ verdade, o que ele rejeita é a noção de partícula para uso nesse âmbito, entendendo que se essa noção for substituída pela de onda pode-se sim falar em identidade e individualidade.

As ondas assim definidas, podem ser individualizadas, abarcam realidades e virtualidades, além de ser eficientes em incorporar as conexões vistas experimentalmente. Explicitando essas três características, Schrödinger mostra que as ondas- $\Psi$ podem substituir partículas, ou ondas ordinárias, ou qualquer construção complementar envolvendo as duas, enquanto entidades de uma ontologia que seja apropriada à descrição dos fenômenos quânticos. 


\section{IOS e a filosofia schrödingeriana: construção da realidade nas esferas cotidiana e científica}

Em outros trabalhos, argumentamos com mais profundidade sobre a construção schrödingeriana dos objetos reais (ver Murr 2010 e 2014). Resumiremos aqui nossa abordagem, que pretende dar forma mais sistemática aos escritos em que Schrödinger se refere ao tema. Nosso intuito, no escopo deste artigo, é enfatizar o papel dessas concepções na formulação de IOS. De fato, a construção das ondas- $\Psi$ revela-se como uma espécie de aplicação das ideias de Schrödinger com respeito à construção de objetos científicos.

É possível dizer que o tratamento dado por Schrödinger ao conceito de realidade ou ao adjetivo 'real' caminhou, ao longo da sua obra, em direção a essa formulação usada para definir as ondas- $\Psi$ como reais. Tomemos, por exemplo, a coparticipação de aspectos reais e virtuais na construção dos objetos, mencionada anteriormente. Começando pelos objetos cotidianos, que constituem o que chamamos de "mundo real ao nosso redor", Schrödinger os define como sendo construídos a partir de "percepções reais e virtuais", já em 1928: "Esta é a realidade que nos cerca: algumas percepções e sensações reais são automaticamente suplementadas por um número de percepções virtuais, e aparecem conectadas em complexos independentes, os quais chamamos de objetos existentes" (Schrödinger 1935 [1928], p.120). Após uma investigação do uso desses termos ao longo de outros textos, podemos dizer que ele se refere a "sensações" e "expectativas", respectivamente (ver Murr 2014, p.40-2). As expectativas conferem, na abordagem de Schrödinger, uma abertura ao objeto real, permitindo dizer que a realidade não é algo pronto e acabado, mas que envolve infinitas possibilidades no âmago da constituição dos objetos. O trecho a seguir mostra a importância das expectativas na constituição do objeto cotidiano, para Schrödinger, em seus textos mais tardios. Referindo-se ao seu próprio braço e sua mão como objetos do 'mundo ao seu redor' (o que entendemos como 'cotidiano' em Schrödinger), ele afirma:

Enquanto objeto material, ele é composto não apenas das minhas sensações diretas dele, mas também das sensações imaginadas que eu teria virando-o, movendo-o, olhando para ele de todos os ângulos diferentes. Também em sua composição adicionamos as percepções que eu imagino que você tenha dele [...] E assim por diante. Não há fim ao se enumerar os percebidos e sensações potenciais do meu e do seu lado que estão incluídas quando falo deste braço como uma característica objetiva do 'mundo real ao nosso redor.' (Schrödinger 1996 [1954], p.94-5).

Os objetos da ciência, para Schrödinger, são configurados exclusivamente por expectativas; as sensações não estão presentes nas descrições científicas (ver Schrödinger 2001 [1956], capítulo 6; 1935 [1928], p.123-5). A característica de abertura

Principia 19(3): 343-361 (2015). 
infinita permanece nos objetos científicos, assim como no caso dos objetos cotidianos, pois essa abertura de possibilidades é fruto da participação das expectativas (ver Murr 2014, p.59 e p.116).

O mais adequado, então, para a entidade básica de uma ontologia em ciência, de acordo com Schrödinger, é que mantenha essa característica de abertura e que comporte essas infinitas possibilidades. As ondas- $\Psi$ se encaixam nessa descrição, devido às infinitas possibilidades que conseguem comportar na sua multidimensionalidade.

Schrödinger é insistente em reiterar que os objetos científicos também devem ser considerados reais. Para ele, se chamamos de reais os objetos cotidianos, que são construídos, também devemos fazê-lo com os científicos. Após a sua argumentação sobre o que torna os objetos ao nosso redor reais, ele afirma: "Acredito que, com respeito aos objetos da ciência, não podemos de fato atribuir outro significado senão aquele há pouco indicado ao conceito de realmente existente." (Schrödinger 1935 [1928], p.120). Ademais, a qualidade 'realidade' está mais ligada à influência que esse objeto tem sobre outros, ou mesmo sobre os sujeitos, servindo de guias de ação e predição, conforme já comentamos (ver Murr 2011, p.89-91).

É possível extrair da filosofia de Schrödinger que a realidade cotidiana e a científica são esferas separadas, não correspondentes, porém não totalmente independentes uma da outra. Elas se interconectam através de algumas 'pontes', as quais estabelecem pontos de contato. No entanto, é importante frisar que essas esferas não são equivalentes. Portanto, a física, por exemplo, não pode ser uma tentativa de explicar como é a realidade cotidiana. As teorias físicas criam outra esfera de realidade, baseada naquela do mundo real ao nosso redor (ver Murr 2014, p.251-260). Para Schrödinger, portanto, nenhuma ontologia científica precisa seguir as mesmas diretrizes da construção dos objetos cotidianos. De fato, nem poderia, já que os objetos cotidianos ainda estão constituídos acomodando sensações.

As sensações são algo faltante na descrição científica, por causa da maneira como a ciência foi constituída, seguindo o que ele chama de "princípio de objetivação". A explicação desse princípio está no trecho a seguir, nas palavras do próprio Schrödinger: "Sem estar conscientes disso e sem ser rigorosamente sistemáticos a respeito disso, excluímos o Sujeito do Conhecimento do âmbito da natureza que nos esforçamos por entender." (Schrödinger 2001 [1956], p.118). Excluindo-se o sujeito, excluem-se também as sensações, embora essas descrições só sejam possíveis com base na coleta de informações vindas de dados sensoriais. Schrödinger dedica muitas reflexões a essa situação gerada pelo princípio de objetivação: na ciência, por exemplo, as teorias estão baseadas em observações, que estão baseadas em sensações de certos sujeitos, e no entanto essas sensações não podem ser encontradas em lugar nenhum da imagem científica do mundo (ver Schrödinger 2001 [1956], capítulo 6).

Há outros aspectos relevantes no panorama schrödingeriano da construção dos objetos, dos quais tratamos nos outros trabalhos de nossa autoria aqui citados. Mas 
as nuances aqui abordadas já permitem notar que a ideia que Schrödinger faz das ondas- $\Psi$ é coerente com as suas concepções gerais a respeito da construção da ontologia do mundo, tanto cotidiano quanto científico. Além disso, a liberdade da sua composição é condizente com a separação feita por Schrödinger dos âmbitos cotidiano e científico, que não precisam equivaler um ao outro nem obedecer aos mesmos princípios. Ele chama de absurdas as tentativas de se misturar os dois tipos de leis: "Na minha opinião é notavelmente absurdo deixar a função de onda ser controlada de duas maneiras inteiramente diferentes, ora pela equação de onda, mas ocasionalmente pela interferência direta do observador, não controlada pela equação de onda." (Schrödinger 1995 [1952a], p.35).

Passemos agora a analisar as outras interpretações da mecânica quântica que nos propusemos a comparar com IOS neste artigo, a fim de perceber especialmente os aspectos dessemelhantes entre elas.

\section{Interpretações de muitos mundos - IMM}

As interpretações conhecidas como IMM da Mecânica Quântica derivam das ideias lançadas por DeWitt em 1970, em um artigo em que ele discute as ideias de Everett (ver Barrett 2014 seção 7). De fato, defende-se que a ideia original de DeWitt pode remontar a Everett (ver Vaidmann 2014, seção 1), embora seja discutível a real aproximação entre essas interpretações. DeWitt e Graham publicam, em 1973, The Many Worlds Interpretation of Quantum Mechanics, em que descrevem a teoria de Everett, associando-a à sua própria interpretação de muitos mundos, a despeito de que o próprio Everett nunca colocou sua interpretação nesses termos. A principal característica de IMM, na versão original de DeWitt, segundo Jeffrey Barrett, é o comprometimento metafísico forte com mundos fisicamente separados (Barrett 2014, seção 7). No caso do experimento de pensamento do gato de Schrödinger, por exemplo, poderíamos considerar que o animal estaria morto em um mundo enquanto que vivo em outro, ambos sendo considerados igualmente reais e ocorrendo simultaneamente, embora fisicamente separados.

Esse experimento de pensamento prevê uma situação de superposição, isto é, uma combinação, no caso do gato, entre os estados 'vivo' e 'morto'. Mais especificamente, a superposição quântica equivale a uma formulação matemática, expressa por uma combinação linear. Essa expressão é válida antes do colapso; no momento da medição, diz-se que o sistema colapsa para um dos estados possíveis. Nesse caso, fazer a medição, ou abrir a caixa onde está o gato, acarreta o colapso do sistema. Há duas opções: encontraremos o gato vivo ou encontraremos o gato morto, ao fazer a medição.

Para IMM, o que ocorre no momento da medição é a realização das possibilidades

Principia 19(3): 343-361 (2015). 
contidas na superposição. No caso do gato, a superposição envolve dois estados, mas é possível uma superposição que envolva um maior número de alternativas. Essas possibilidades se realizariam, de acordo com a IMM, em cada mundo distinto, concomitantemente. O que explica que vejamos apenas uma delas, em nossa experiência sensível, é estarmos olhando sempre da perspectiva do mundo em que estamos inseridos. Há duas variantes dessa interpretação: a de que esse mundo é centrado em nosso ser sensível e a de que ele se refere ao presente. Muitos mundos, segundo essa última vertente, são referentes apenas ao futuro. O momento da medição (presente) e o passado já determinam um desses mundos. Logo não seria possível, para quem está inserido em um deles, enxergar os outros (futuro). Em ambas as versões, essa interpretação visa a explicar a experiência dos seres sensíveis e sua concepção de mundo à luz da mecânica quântica (Vaidman 2014, seção 2.1). Por isso, os mundos que estão, por assim dizer, para além da experiência possível desses seres são apenas imagináveis ou teorizáveis, mas não experienciáveis.

\section{Interpretação de Everett: formulação do estado relativo}

A versão mais curta da tese de Everett, Wave Mechanics without Probability, foi publicada em 1957 (ver Barrett 2014, seção 1); um artigo intitulado "Relative State Formulation of Quantum Mechanics" foi também publicado no mesmo ano (Everett 1957). Segundo Barrett, o objetivo de Everett era eliminar o colapso, e sua respectiva dinâmica, da formulação padrão da mecânica quântica (Barrett 2014, seção 1). A rejeição do colapso implicaria, então, trabalhar apenas com a parte contínua da teoria, a saber, as suas expressões em termos de mecânica ondulatória (ele chamou a sua nova teoria de "mecânica ondulatória pura"). O colapso, nessa acepção, passa a ser explicado como algo concernente à experiência de um observador. Os resultados das medições conferem com os da formulação padrão de von Neumann-Dirac, pois Everett resgata as predições desses resultados colocando os próprios observadores como sistemas físicos sujeitos às leis da pura mecânica ondulatória (Barrett 2014, seção 3). Sendo assim, Everett reintroduz o colapso apenas com o intuito de explicar o registro determinado por parte do observador após a medição, mesmo diante de uma situação de superposição que pode ser descrita através da mecânica ondulatória. A explicação para esse registro é que parece, a um observador ideal, que os resultados são absolutamente determinados; ele não se dá conta dos estados relativos (Barrett 2014, seção 5.2).

A ideia da superposição entre aparato e sistema quântico vista no experimento do gato de Schrödinger apresenta de fato semelhanças para com a formulação de Everett dos estados relativos, pois este cria funções para o observador e para um "observador do observador" (ver Barrett 2014, seção 5.2 - história do "Amigo de Wigner") e

Principia 19(3): 343-361 (2015). 
representa superposições delas para escapar ao colapso e ao problema da medição. Porém, mais uma vez vale frisar que o observador não fazia parte dessa superposição, para Schrödinger; ele não vê com bons olhos esse tipo de emaranhamento entre objetos cotidianos e científicos. Já Everett parece ter aceitado esse tipo de superposição 'mista' entre objetos científicos e cotidianos, quando expressa através de uma função de onda o estado do observador somado ao sistema quântico.

Independentemente dos detalhes concernentes à formulação matemática da teoria de Everett e sua interpretação física, que não serão abordados aqui (ver Barrett 2014 e Everett 1957 para maiores detalhes) uma característica fundamental de sua base filosófica subjacente precisa ser ressaltada, a fim de evidenciar a diferença principal para com a Interpretação de DeWitt. Trata-se da "confiabilidade empírica", traço marcante da visão de Everett com respeito à ciência, o qual se encontrava refletido em sua descrição da mecânica quântica sem colapso. Para ele, não fazia sentido se perguntar se uma teoria é verdadeira em ciência; uma teoria científica seria apenas uma construção. É possível ter um modelo construído pela ciência para o mundo externo, podendo-se identificar um homomorfismo de ambos; nesse caso, a teoria pode ser dita "empiricamente adequada" ou "empiricamente confiável" (Barrett 2014, seção 4). Não há, portanto, na formulação de Everett, o mesmo comprometimento metafísico que aparece na interpretação de muitos mundos de DeWitt.

De posse dessa visão geral das três interpretações abordadas neste artigo, podemos agora proceder à comparação que nos levará a uma conclusão sobre as suas diferenças e semelhanças.

\section{IMM, Everett e IOS: comparações}

Conforme já mencionamos, DeWitt acabou divulgando uma leitura particular do texto de Everett. Barrett afirma, referindo-se a DeWitt: "Dito isso, ele promoveu fortemente a teoria o tempo todo, e as visões de Everett rapidamente vieram a ser identificadas com a interpretação de muitos mundos de DeWitt e Graham." (Barrett 2014, seção 7). Já apontamos uma dessemelhança entre essas perspectivas, quanto à interpretação metafísica dos mundos: enquanto para Everett não há comprometimento metafísico forte, para DeWitt os muitos mundos parecem ser possibilidades metafísicas separadas. Além dessa diferença apontada pelo próprio Everett, é possível afirmar que DeWitt também via, inicialmente, vários pontos de divergência entre o seu enfoque e o de Everett. Em especial, DeWitt pensava que a descrição de Everett propunha um mundo "muito rico", que não poderia fornecer um modelo correspondente à realidade empírica de um único mundo (Barrett 2014, seção 4).

Fundamentalmente, trata-se do mesmo problema que no caso anterior, em que DeWitt e Everett discordavam quanto ao grau de verdade que poderia ser atribuído a

Principia 19(3): 343-361 (2015). 
uma teoria científica. Em outras palavras, eles discordavam quanto a uma premissa filosófica fundamental: a adoção ou não de uma espécie de realismo científico. $\mathrm{O}$ tipo de realismo científico adotado por DeWitt exigia as explicações através de muitos mundos, todos eles igualmente reais e ocorrendo ao mesmo tempo. No caso de Everett, podemos dizer que ele adota uma espécie de instrumentalismo. Suas afirmações quanto à não-exigência de correspondência dos modelos científicos para com a realidade e sua defesa da confiabilidade empírica como substituta da verdade corroboram essa posição.

Nas duas interpretações, o colapso da função de onda, conforme comumente concebido, é em alguma medida abalado. Enquanto Everett de certa forma mascara o colapso na teoria, incluindo-o como experiência subjetiva do observador, DeWitt consegue trivializá-lo, na medida em que considera que todas as possibilidades se realizam, em mundos distintos, e não apenas uma realizada no momento da observação, em um certo mundo.

Comparando Everett e IOS, vemos que a adoção explícita da mecânica ondulatória, além da rejeição do colapso como tradicionalmente concebido pela interpretação ortodoxa da teoria quântica, aproximam Everett e Schrödinger, de fato sugerindo alguma inspiração vinda da interpretação ondulatória schrödingeriana. Porém, é possível notar várias diferenças entre essas interpretações. A primeira que podemos apontar diz respeito à solução de Everett, que introduz o colapso na experiência do observador, usando para isso o subterfúgio de mesclar objetos cotidianos e científicos, além do próprio sujeito. Para Schrödinger, a objetivação científica, além da diferença estrutural de objetos científicos e cotidianos, impedem essa manobra. Outras diferenças concernem a concepção física e ontológica da função de onda. É necessário relembrar que para Schrödinger toda a estrutura ontológica precisava ser alterada desde as suas entidades básicas, para que se eliminassem os problemas advindos da concepção clássica de partícula ou mesmo de onda, descrições ainda utilizadas para lidar com fenômenos quânticos. Por isso, ele defendia a substituição da entidade ontológica básica pelas ondas- $\Psi$.

No caso de DeWitt, também percebemos diferenças essenciais para com IOS, especialmente no que concerne à multiplicação de mundos possíveis. Para Schrödinger, as infinitas possibilidades pertencem a um único mundo e devem ser nele atendidas. Conforme já vimos, as ondas- $\Psi$ contemplam já em sua constituição as possibilidades de uma realidade aberta, aspecto fundamental de sua construção, para Schrödinger. Não há necessidade de multiplicar os mundos, trivializando assim o colapso, que deve ocorrer em cada um deles.

A partir dos argumentos apresentados ao longo deste artigo, é possível notar que as duas interpretações, IMM e de Everett, não são equivalentes e ainda exibem diferenças substanciais. As várias nuances e características peculiares da interpretação de Schrödinger, já apresentadas, também a diferenciam das duas interpretações cita- 
das. Assim, delineamos a argumentação proposta inicialmente, em que sustentamos que não é possível derivar essas interpretações umas das outras. Consequentemente, seria inadequado afirmar que IMM deriva de IOS. Podemos dizer que há uma cadeia de inspiração que leva de uma interpretação à outra, mas que essa inspiração deve residir somente no fato de que todas as três questionaram de alguma forma a interpretação dominante da mecânica quântica com respeito ao colapso. Nesse sentido, Schrödinger pode ser considerado como um pioneiro da rejeição ao colapso quântico ortodoxo.

\section{Considerações finais}

$\mathrm{Na}$ abordagem schrödingeriana aqui discutida ambos os aspectos da realidade, cotidiano e científico, são parte de um mesmo mundo. Este apenas se encontra dividido como consequência do desenvolvimento da ciência ocidental, que gerou uma inflação ontológica capaz de criar mais esferas dentro desse mundo considerado real. Não se trata de mundos distintos, ou de mundos possíveis. Estamos falando de um e o mesmo mundo, embora composto por várias esferas diferentes.

No caso das ondas- $\Psi$, elas contêm infinitas possibilidades; estas se realizam simultaneamente ao constituir um objeto aberto como é típico de um objeto científico, para Schrödinger. De certa forma, essa concepção se assemelha à de Everett, considerando-se que, para ele, também não parece haver correspondência entre os modelos científicos e a realidade empírica. A diferença está no realismo científico específico de Schrödinger, que mesmo assim consideraria as ondas- $\Psi$ como reais, ao contrário de Everett, que ao que tudo indica considera os construtos científicos apenas como construções lógicas ou modelos no sentido lógico, de maneira mais próxima a um instrumentalismo científico. Outra afinidade entre as duas perspectivas é a incorporação das possibilidades pela teoria, já que Everett trabalha também com a mecânica ondulatória, em uma formulação que ele chama de 'pura'. No entanto, para ele, a experiência do observador só permite pensar na realização de uma das possibilidades, por isso o colapso. Ao que parece, Schrödinger concordaria com isso, em certo sentido, uma vez que a experiência do observador se encontra fora da esfera científica e é parte do mundo cotidiano, em que as leis não são as mesmas que na mecânica quântica. No mundo cotidiano, que constitui o mundo empírico em que o aparato experimental está inserido, o colapso e as descontinuidades ocorrem, sendo que uma das possibilidades se mostra ao observador, ao realizar a medição. Afinal, para o sujeito observador é preciso classificar e caracterizar a sua experiência, de acordo com os seus próprios padrões.

A dificuldade de Schrödinger estava em explicar esse momento de descontinuidade, ou em tentar incorporá-lo à teoria quântica, mantendo as mesmas leis regentes

Principia 19(3): 343-361 (2015). 
das suas funções de onda. O problema tomou dimensão tão importante na filosofia da física quântica de Schrödinger que é comentado por seus biógrafos. Gribbin, por exemplo, ressalta o que já comentamos: Schrödinger não aceitava que a função de onda fosse descontinuada apenas pelo nosso olhar para ela; ela devia ser regida sempre pelas mesmas leis, não por vezes seguir uma lei e por vezes outra (Gribbin 2003, p.653-7). Mesmo diante desse impasse, e concedendo uma certa aproximação, é preciso salientar que Schrödinger provavelmente não concordaria com a inserção do sujeito na teoria física, como faz Everett; as abordagens dos dois têm fundamentos muito diferentes. Isto é, ainda que a solução de Everett aparentemente resolva o problema da medição, cremos que Schrödinger não a adotaria, tendo em vista a relevância de outros pressupostos para o todo do seu pensamento.

Quanto à IMM, sugerimos que esta não é condizente com IOS por um motivo principal: IMM mantém um esquema clássico de raciocínio, em certo sentido. Na solução dada pelos muitos mundos, temos que cada mundo é regido pelas mesmas leis clássicas no momento da observação, sendo que o colapso ocorre em cada um deles. Isso não força mudança de parâmetros, mas apenas se constitui em uma solução hábil que consegue manter os mesmos padrões de racionalidade que envolvem uma construção fechada do objeto real. IOS, bem como a filosofia de Schrödinger em geral, propõem alteração de padrões. A superposição quântica, por exemplo, é uma situação epistemológica - e pode-se dizer ontológica - peculiar, não se equiparando a nada com que estejamos acostumados a lidar no âmbito cotidiano. Apresentando-nos essa situação, a física quântica oferece uma oportunidade de assumir atitudes ousadas, do ponto de vista filosófico, em lugar dos antigos métodos e arranjos a fim de solucionar situações novas as quais não se consegue, de início, estruturar.

As ondas- $\Psi$ avançam em direção a uma nova concepção do que é um objeto, concepção esta condizente com os outros desenvolvimentos filosóficos de Schrödinger, que em geral também sugerem a quebra (embora não radical) de certos padrões de racionalidade. Notemos que ele não incentiva que a física abandone a própria noção de que o mundo seja composto por objetos, isto é, de um "mundo objetivado", ainda que sugira que filosoficamente é importante repensar a dualidade entre sujeito e objeto: "Embora tenhamos que aceitá-la no cotidiano 'para referência prática', devemos, assim acredito, abandoná-la no pensamento filosófico.” (Schrödinger 2001 [1956], p.127).

A mecânica quântica seria, seguindo Schrödinger, uma oportunidade de se prestar atenção a padrões que podem ser modificados, ainda que somente para o âmbito científico e com cuidado. As controvérsias levantadas sobre a causalidade, por exemplo, se constituíam para ele em "uma fase em nossa mudança de atitude intelectual" (Schrödinger 1935, p.42). Esse comentário leva a crer, somado às ideias por ele apresentadas em seus outros textos, que para Schrödinger o intelecto humano não é estruturado por um padrão fixo, mas sim maleável e cheio de possibilidades a serem 
exploradas. Consequentemente, a própria realidade, cuja estruturação é fruto desses esquemas intelectuais, também apresenta essas características. Mas essa exploração deve ser feita com cuidado, para que não se percam as conquistas positivas da humanidade, do ponto de vista científico, intelectual e cultural, alcançadas até então (ver Schrödinger, 2001 [1956], capítulo 4).

Por fim, vale salientar que o enfraquecimento da conexão de IMM com a filosofia de Schrödinger parece vantajosa em vários aspectos. Em primeiro lugar, essa visão está mais próxima da interpretação que temos para a filosofia schrödingeriana, conforme mostrou nossa argumentação neste artigo, inclusive considerando a sua visão sobre a mecânica quântica e a ontologia que para esta Schrödinger propunha. Depois, trata-se de uma visão ontológica mais econômica, que não precisa dos muitos mundos para dar conta dos aspectos filosóficos da questão da superposição e outros pormenores da mecânica quântica não-relativística. Por último, o tratamento schrödingeriano das inusitadas situações quânticas sugere desenvolvimentos epistemológicos mais originais e mais vantajosos para o ser humano em termos de desenvolvimento intelectual, uma vez que visam à flexibilização de certos padrões vistos como fixos.

\section{Referências}

Allorri, V.; Goldstein, S.; Tumulka, R.; Zanghi, N. 2011, Many-Worlds and Schrödinger's First Quantum Theory. British Journal for the Philosophy of Science 62: 1-27.

Barrett, J. 2014. Everett's Relative-State Formulation of Quantum Mechanics. In: E. N. Zalta (ed.) The Stanford Encyclopedia of Philosophy (Fall 2014 Edition). URL $=<$ http://plato. stanford.edu/archives/fall2014/entries/qm-everett/>. Accessed in 28/10/2014.

Bitbol, M. 1995. Introduction. In: M. Bitbol (org.) 'The Interpretation of Quantum Mechanics: Dublin Seminars (1949-1955)' and Other Unpublished Essays, p.1-18. Woodbridge: Ox Bow Press.

DeWitt, B.; Graham, N. (eds.) 1973. The Many-Worlds Interpretation of Quantum Mechanics. Princeton Series in Physics. Princeton: Princeton University Press.

Everett, H. 1957. 'Relative State' Formulation of Quantum Mechanics. Reviews of Modern Physics 29: 454-62.

French, S.; Krause, D. 2006. Identity in Physics: a Historical, Philosophical and Formal Analysis. New York: Oxford University Press.

Gribbin, J. 2013. Erwin Schrödinger and the Quantum Revolution. New Jersey: Wiley \& Sons. Moore, W. 1989. Schrödinger: life and thought. New York: Cambridge University Press.

Murr, C. 2010. Física Quântica e Objetividade Científica: Algumas ideias filosóficas de Erwin Schrödinger. Dissertação de Mestrado. Florianópolis: Universidade Federal de Santa Catarina, Programa de Pós-Graduação em Filosofia.

— 2011. O Realismo Científico Schrödingeriano. In: L. H. Dutra; A. M. Luz (orgs.) Linguagem, Ontologia e Ação. Coleção 'Rumos da Epistemologia' 10, p.85-91. Florianópolis: NEL - Núcleo de Epistemologia e Lógica.

Principia 19(3): 343-361 (2015). 
2014. A Realidade Através do Espelho: Schrödinger e Russell no País da Objetivação. Tese de Doutorado. Florianópolis: Universidade Federal de Santa Catarina, Programa de Pós-Graduação em Filosofia.

Pessoa Jr., O. 2003. Conceitos de Física Quântica. Vol. 1. 3 ed. São Paulo: Editora Livraria da Física.

Schrödinger, E. 1935 [1928]. Conceptual Models in Physics and their Philosophical Value. In: Science and the Human Temperament, p. 119-38. Tradução de J. Murphy. London: George Allen \& Unwin Ltd.

- 1935. The Law of Chance. In: Science and the Human Temperament, p.33-42. Tradução de J. Murphy, J. London: George Allen \& Unwin Ltd.

— 1995 [1949]. Notes for 1949 Seminar. In: M. Bitbol (org.) 'The Interpretation of Quantum Mechanics: Dublin Seminars (1949-1955)' and Other Unpublished Essays, p.97-107. Woodbridge: Ox Bow Press.

1996 [1951]. Science and Humanism: Physics in Our Time. In: 'Nature and the Greeks' and 'Science and Humanism', p.101-72. Cambridge: Cambridge University Press.

—. 1995 [1952a]. July 1952 Coloquium. In: M. Bitbol (org.) 'The Interpretation of Quantum Mechanics: Dublin Seminars (1949-1955)' and Other Unpublished Essays, p.19-38. Woodbridge: Ox Bow Press.

— 1995 [1952b]. Transformation and Interpretation in Quantum Mechanics. In: M. Bitbol (org.) 'The Interpretation of Quantum Mechanics: Dublin Seminars (1949-1955)' and Other Unpublished Essays, p.39-95. Woodbridge: Ox Bow Press.

— 1996 [1954]. Nature and the Greeks. In: 'Nature and the Greeks' and 'Science and Humanism', p.1-99. Cambridge: Cambridge University Press.

_ 1995 [1955]. Notes for 1955 Seminar. In: M. Bitbol (org.) 'The Interpretation of Quantum Mechanics: Dublin Seminars (1949-1955)' and Other Unpublished Essays, p.109-20. Woodbridge: Ox Bow Press.

- 2001 [1956]. Mind and Matter. In: 'What is life?' with 'Mind and Matter' and 'Autobiographical Sketches', p.123-49. Cambridge: Cambridge University Press.

Vaidman, L. 2014. Many-Worlds Interpretation of Quantum Mechanics. In: E. N. Zalta (ed.) The Stanford Encyclopedia of Philosophy (Winter 2014 Edition). URL $=<$ http://plato.stan ford.edu/archives/win2014/entries/qm-manyworlds/>. Accessed in 28/10/2015.

\section{CARoline Elisa Murr Universidade Federal do Paraná \\ UFPR \\ caromurr@gmail .com}

\section{Notas}

${ }^{1}$ Doravante no texto nos referiremos a essa interpretação simplesmente como "IMM".

${ }^{2}$ Nos referiremos como "IOS" a essa interpretação, daqui por diante no texto.

${ }^{3}$ A tradução das citações para o português é de nossa autoria em todos os casos.

${ }^{4}$ Para mais detalhes sobre complementaridade em Bohr, ver Pessoa Jr. 2003, p.91-8.

${ }^{5}$ Ver Murr 2014, p.73-80 e French \& Krause 2006, seção 3.6, para comentários sobre identidade em Schrödinger.

Principia 19(3): 343-361 (2015). 